Research Article

\title{
Study on the Effect of Different Delamination Defects on Buckling Behavior of Spar Cap in Wind Turbine Blade
}

\author{
Jianwei Li, ${ }^{1}$ Jinghua Wang ${ }^{D},{ }^{1}$ Leian Zhang, ${ }^{1}$ Xuemei Huang, ${ }^{1}$ and Yongfeng $Y u^{2}$ \\ ${ }^{1}$ School of Mechanical Engineering, Shandong University of Technology, Zibo 255049, China \\ ${ }^{2}$ Lianyungang Zhongfu Lianzhong Composites Group Co., Ltd., Lianyungang 222002, China \\ Correspondence should be addressed to Jinghua Wang; wangjh0102@163.com \\ Received 7 June 2020; Revised 18 August 2020; Accepted 12 September 2020; Published 1 October 2020 \\ Academic Editor: Dimitrios E. Manolakos \\ Copyright (c) 2020 Jianwei Li et al. This is an open access article distributed under the Creative Commons Attribution License, \\ which permits unrestricted use, distribution, and reproduction in any medium, provided the original work is properly cited. \\ Delamination is detrimental to the composite materials, and it may occur in the manufacturing process of the unidirectional \\ laminate of the spar cap in wind turbine blades. This paper studies the effect of different delamination defects on the strength of the \\ unidirectional laminate. The finite element model of laminate with different delamination areas and delamination heights is \\ established using solid elements. The eigenvalues of laminates have different parameters calculated based on the finite element \\ method. The final coupon test is used to verify the conclusions of simulation results. The finite element method presented in this \\ study shows excellent capabilities to predict the buckling behavior of the laminate. The buckling eigenvalue of tested laminate is \\ negatively correlated with the delamination area and positively correlated with the delamination height under the edgewise load. \\ The $S 11$, which is too high at the boundary of the delamination region, plays a significant role in buckling failure. It has a particular \\ reference value for testing the laminate of blade both in theory and practice.
}

\section{Introduction}

Wind turbine blades rely on its aerodynamic shape to convert wind energy into electrical energy during the operation condition. Its ultimate strength plays a significant role in stable operation, especially the spar cap and shear web $[1,2]$. Some studies [3-5] have reported the performance of the material of the spar cap and web. In engineering applications, it is found that the delamination defects of UDL (unidirectional laminate) generated in manufacturing or transportation will reduce the strength of the spar cap. Material defects lead to premature failure of blades when subjected to the identified load in static tests or fatigue tests [6-14]. Some studies present that delamination and other defects caused by stress will significantly reduce the blade's global performance, especially the buckling at the trailing edge [15-17].

To study the buckling performance of blade materials, the published test standards $[18,19]$ include the full-scale test method, subcomponent test method, and coupon test method in Figure 1. The full-scale test is performed on an intact blade in order to verify the load carry capability and service life of the blade. The full-scale test does not aim at specific areas and types of damage. The subcomponent test is performed on a segment of the blade in order to determine the limited failure types of the selected subcomponent. The coupon test is performed on some small specimens with primary material used in the blade in order to determine the selected failure type of tested materials, which makes the research more relevant.

In [20], the subcomponent test was conducted to study the influence of the laminate with wrinkle defects on the adhesive joint's structural performance. Finally, according to the subcomponent test results, the effect of the wrinkle defect on the blade is evaluated reasonably. In [21], the coupon test was conducted to study the compression performance of C-beam. Based on the bonding performance of bonding paste connecting the spar cap and the laminate, the impact of bonding paste on the blade structure is evaluated. Therefore, the coupon test is a useful choice for the study of buckling performance of blade materials.

The test target of coupon test is the sample, and some studies have reported their finding on defect samples. In 
[22], it is noted that different delamination defects in materials would cause different types of buckling, including local buckling and global buckling. Different types of delamination have different influences on the structural performance of a spar cap. In [23], Wang et al. tested the samples with delamination defects and pointed out that the process of material buckling experienced three stages: inplane deformation stage, local buckling stage, and global buckling stage. Moreover, the delamination extension caused by buckling is the primary cause of material failure. In [24, 25], Gong et al. established the samples' model by using the solid element (C3D8) to identify the stress response of the samples with delamination defects. FEM (finite element method) is used in this test, and it shows the details of the delamination extension. The final test shows an excellent agreement with a simulation, which indicates that FEM can be used to study the performance of materials. In [26], laminates with delamination have been further studied in composite materials, and the extension behavior of delamination is explained in detail. In [27], FEM was used to analyze the materials to study the structural performance of cylindrical shells with defects. The buckling eigenvalues were used to characterize the properties of the samples with defects.

According to $[24,25,28]$, delamination defects tend to accelerate the buckling instability of materials. Unfortunately, the exact relationship between buckling and delamination is not explained. This study provides a new understanding of the buckling failure of a UDL with different delamination defects used in the spar cap of wind turbine blades.

The test data presented in [24-27] show that the FEM has a good effect on coupon test. The test in $[27,29]$ shows that it is efficient to determine the material performance by buckling eigenvalues. FEM and coupon test were carried out to get the effects of different delamination defects on the UDL of the spar cap. Specimens are subjected to pressure force, which made the structure of UDL unstable rapidly. The buckling eigenvalues of the structure were calculated, and then, the relationship between the different delamination types and buckling behavior of materials is evident.

\section{Spar Cap with Delamination}

2.1. Spar Cap and Materials. The spar cap and shear web's material performance play a significant role in the structural strength of wind turbine blades. The combination of the two components named box beam (see Figure 2) ensures the smooth operation of blades [30-32]. The spar cap is made of UDL composed of glass fiber fabric (GFF) and matrix resin. The shear web is made of sandwich panels composed of biaxial laminate and balsa wood, and the sandwich structure plays a significant role in resisting the shear load on blades. In working condition, the blade is loaded by the flapwise load caused by wind pressure, which makes the spar cap subjected to the tension and pressure load along the axial of fiber.

Meanwhile, the blade is loaded by the edgewise load caused by gravity and bending moment, making the spar cap

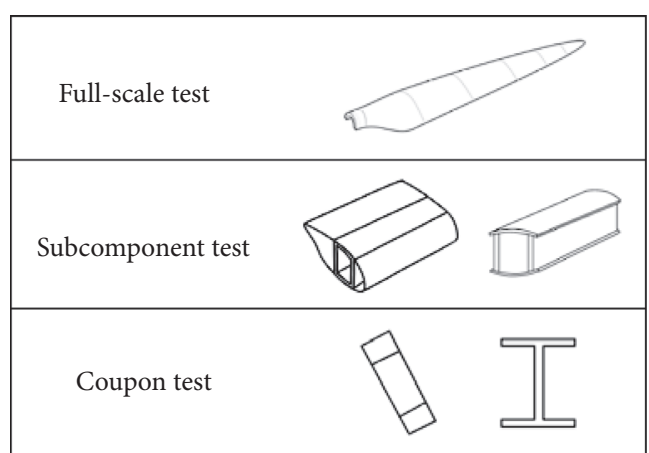

Figure 1: Test methods of the wind turbine blade.

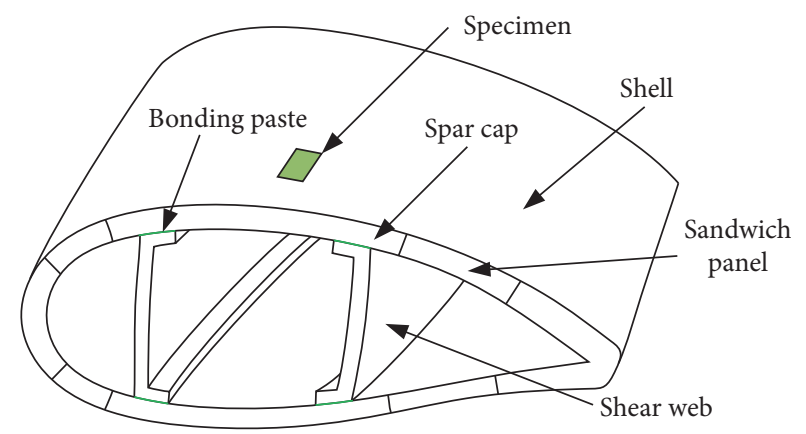

Figure 2: Components of the blade.

subject to the transverse load perpendicular to the axial of fiber. The transverse load is the principal cause that inflicts instability of the spar cap. The shear web has resisted the spar cap's buckling to a certain extent, so the buckling eigenvalue of UDL will decrease with the cracking of the adhesive joint.

The typical UDL used in the blade is the GFRP (glass fiber reinforced polymer composites) composed of GFF (glass fiber fabric) and matrix resin by vacuum infusion. The material properties of UDL are listed in Table 1, where the subscripts $t$ and $c$ present tension and compression, respectively.

The nonstandard manufacturing and low-speed impact on the products are often the primary reason for the delamination close to the midsurface of the UDL used in the spar cap. The stress on the space (see Figure 3(a)) is mainly caused by the interaction between the plyer boundaries on both sides of the crack: package and the high-speed impact are often the primary reasons for the delamination close to the surface. The layer near the convex side (see Figure 3(b)) has a higher probability of breaking away from the constraint of the matrix and damage. The variates under two different delamination defects include the height $(h)$, the width $(a)$, and length $(b)$ of delamination.

2.2. FE Model. The CAD model of UDL with different delamination defects was established to obtain the stress nephogram of UDL layer by layer and study the general rules of the effect on buckling behaviors imposed by different delamination types. Gong et al. [24, 25] stated that the solid element could accurately capture the simulation results in 
TABLE 1: Material properties of UDL.

\begin{tabular}{lccccccccccc}
\hline$E_{1}(\mathrm{GPa})$ & $E_{2}, E_{3}(\mathrm{GPa})$ & $v_{12}, v_{13}$ & $v_{23}$ & $G_{12}, G_{13}(\mathrm{MPa})$ & $G_{23}(\mathrm{MPa})$ & $X_{\mathrm{t}}(\mathrm{MPa})$ & $X_{\mathrm{c}}(\mathrm{MPa})$ & $Y_{\mathrm{t}}(\mathrm{MPa})$ & $Y_{\mathrm{c}}(\mathrm{MPa})$ & $S_{\beta}(\mathrm{MPa})$ & $h(\mathrm{~mm})$ \\
\hline 44.6 & 14.3 & 0.28 & 0.44 & 4160 & 3000 & 1100 & 774 & 29.2 & 137.6 & 99 & 0.5 \\
\hline
\end{tabular}

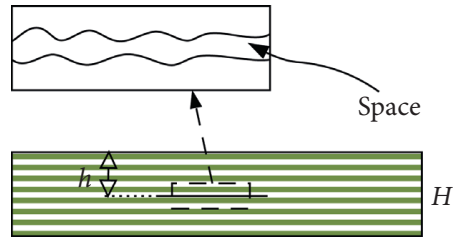

(a)

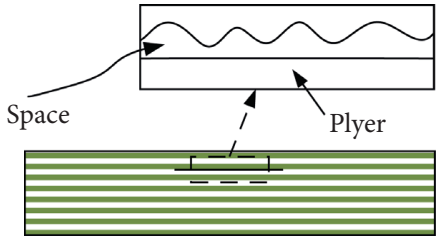

(b)

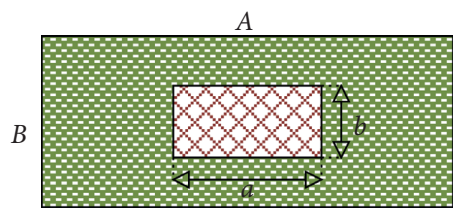

(c)

FiguRE 3: Different delaminations of UDL: (a) delamination close to the midsurface; (b) delamination close to the surface; (c) plan view of delamination.

FEM. So the hex mesh has been used in the FE model of UDL. Furthermore, a reduced integration algorithm can be used in hex mesh (C3D8), and a more accurate uniform strain formula can be used to avoid element disturbance. A hex mesh can consume fewer integration steps compared with the complete integration algorithm. This project establishes the single-shell model of the specimen of this study based on hex mesh. A UDL with a thickness of $8 \mathrm{~mm}$ is set by using mesh-solid offset, and the sweeping direction is the vertical direction of the ply. The tie constraint is used to establish the ply with different heights.

By comparing the calculated eigenvalues and the stress response of each layer, the influence of different layers on the structural behavior of UDL under working conditions can be reasonably inferred. The FE model in Figure 4(a) pointed the set direction, where $S$ represents the shear force and the direction $1 / 2 / 3$ represents the direction along with the glass fiber. The direction and thickness parameters of the layer are shown in Figure 4(b).

\section{Numerical Theories for Buckling Eigenvalues}

Set the length of the plane perpendicular to the fiber direction 3 as $a$ and the width as $b$. The buckling load can be calculated in FE analysis according to equation (1) proposed by Bisagnit [33]:

$$
\bar{N}_{x}=\pi^{2}\left[D_{11}\left(\frac{m}{a}\right)^{2}+2\left(D_{12}+D_{66}\right)\left(\frac{n}{b}\right)^{2}+D_{22}\left(\frac{n}{b}\right)^{4}\left(\frac{a}{m}\right)^{2}\right] \text {, }
$$

where $\bar{N}_{x}$ described the ultimate buckling load per unit area, $D_{i j}$ described the strength factor related to bending stiffness in classical lamination theory, and $m$ and $n$ described the numbers of buckle half-wavelength of material in fiber direction 2 and direction 1 in Figure 3, respectively.

Assuming $n=1$, calculating the first derivative with respect to $m$, then the following equation is obtained:

$$
\frac{\partial N_{0}(m, 1)}{\partial m}=2 \pi^{2}\left[D_{11} \frac{m}{A^{2}}-\frac{D_{22}}{B^{4}} \frac{A^{2}}{m^{3}}\right]=0 .
$$

Thus, the relationship between $m$ in equation (3) and known parameters can be obtained. When $n=1$, the buckling load can be calculated in the first-order buckling mode. Other numbers can be calculated according to equations (1) (3):

$$
m=\frac{A}{B} \sqrt[4]{\frac{D_{22}}{D_{11}}}
$$

\section{Results and Discussion}

4.1. Buckling Values. The FE software is used to simulate the UDL with different delamination defects. Table 2 lists the buckling eigenvalues in this work. The first six orders of buckling eigenvalues of the specimen with no defects are [43.203, 97.997, 107.66, 139.63, 176.45, 199.00]. Under the same height, there is a significant negative correlation between the delamination area and the buckling eigenvalue. The larger the delamination area is, the earlier the buckling failure occurs. Based on the relationship between the different heights of specimens and the eigenvalues, the delamination defect closer to the surface has lower eigenvalues. Meanwhile, under the same delamination area, the smaller the height $h$ is, the lower the buckling eigenvalue is.

4.2. Results of Simulation. To study the effect of delamination area and height on buckling behavior of UDL, specimens $[20 * 20-1 / 30 * 30-1 / 40 * 40-1]$ and $[40 * 40-4 / 40 * 40-3 / 40 * 40-2 / 40 * 40-1]$ were taken to compare the buckling parameters and results. The effect of different parameters of UDL on the buckling eigenvalues and material stress response is explored, based on the simulation results. The nephogram of specimens in Figures 5 and 6 shows the stress and deformation of UDL. In order to get a more intuitive result, the midsections of UDL are shown in the nephogram.

The buckling eigenvalue of the specimens in Figure 5 and the stress of UDL are negatively correlated with the delamination area at the same delamination height $h$, which corresponds to the data in Table 2. The specimens in Figure 5 


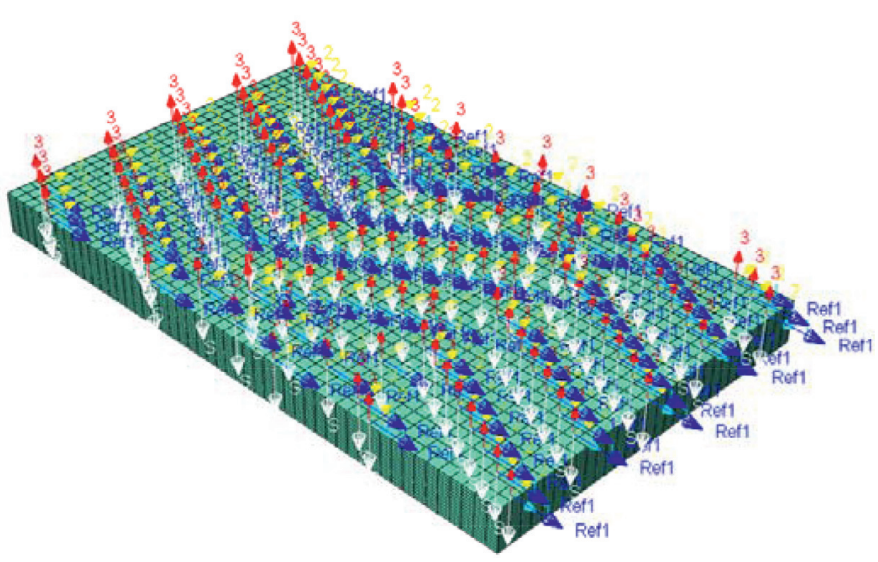

(a)

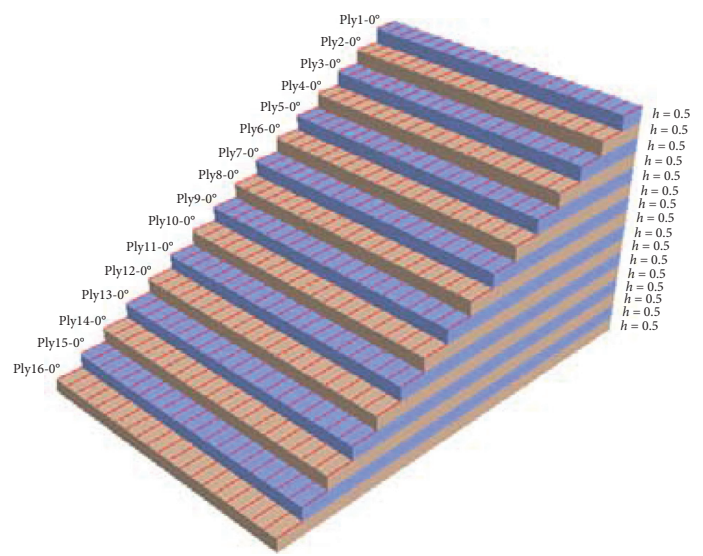

(b)

Figure 4: Setup of UDL: (a) the set direction in FE model; (b) layer parameters.

TABLe 2: Buckling eigenvalues of FE analysis.

\begin{tabular}{|c|c|c|c|c|c|}
\hline & Order & $h=4$ & $h=3$ & $h=2$ & $h=1$ \\
\hline \multirow[t]{6}{*}{ Delaminate area $20^{*} 20$} & 1 & 42.636 & 42.623 & 42.534 & 38.201 \\
\hline & 2 & 95.355 & 95.345 & 94.391 & 43.334 \\
\hline & 3 & 103.06 & 103.01 & 102.08 & 60.397 \\
\hline & 4 & 137.08 & 137.02 & 121.94 & 85.139 \\
\hline & 5 & 165.22 & 165.05 & 137.94 & 87.243 \\
\hline & 6 & 197.16 & 197.08 & 158.38 & 95.791 \\
\hline \multirow[t]{6}{*}{ Delaminate area $30 * 30$} & 1 & 41.226 & 41.153 & 41.070 & 18.191 \\
\hline & 2 & 88.140 & 88.092 & 64.774 & 28.951 \\
\hline & 3 & 91.639 & 91.162 & 88.945 & 40.451 \\
\hline & 4 & 129.28 & 120.32 & 91.391 & 40.729 \\
\hline & 5 & 143.57 & 129.92 & 105.68 & 42.803 \\
\hline & 6 & 176.95 & 148.75 & 126.07 & 53.590 \\
\hline \multirow{6}{*}{ Delaminate area $40 * 40$} & 1 & 37.651 & 37.136 & 36.486 & 10.640 \\
\hline & 2 & 76.330 & 73.187 & 43.620 & 16.981 \\
\hline & 3 & 78.337 & 77.827 & 59.469 & 23.830 \\
\hline & 4 & 113.55 & 87.960 & 76.912 & 23.844 \\
\hline & 5 & 118.89 & 113.47 & 83.001 & 31.163 \\
\hline & 6 & 119.31 & 116.76 & 92.039 & 37.284 \\
\hline
\end{tabular}

made a local buckling, which results in the stress concentration at the delamination boundary. The high stress is distributed at the delamination boundary and the deformation region at the top. The layer under the delamination area has low stress and almost no deformation.

Because of the lower material performance at the top, local buckling has lower resistance to occur in layers close to the surface, which is one of the common reasons for blade damage. The proportion of unstable materials increases with the accumulation of the delamination area. The local buckling of the layer results in the stress concentration in the defect area, which affects the mechanical performance of UDL. Buckling destroys the stability of the spar cap and makes it failed, and the influence of defects on the structural failure increases significantly with the accumulation of the delamination area.

The buckling eigenvalue of the specimens has the same delamination area in Figure 6, and the stress of the material is negatively correlated with the height $h$. The failure type of specimens [ $40 * 40-4 / 40 * 40-3$ ] is global buckling, and the others are local buckling. Although the specimen [40*40-2] with a large delamination area shows local buckling, it still has a high eigenvalue. The delamination height $h$ is the thickness of the unstable material. When the thickness reaches a certain degree, the failure type of UDL with delamination defects will not be local buckling, but global buckling. Full buckling will make the ultimate strength of UDL in a higher range. There is no stress concentration at the top of the buckling deformation of specimen [ $40 * 40-2$ ] with local buckling, only at the boundary of delamination. The simulation results of specimens $[40 * 40-2 / 40 * 40-1]$ show that the stress concentration at the top of the deformation area has a stronger influence on the buckling eigenvalue's numerical value. The overall simulation results in Figure 6 show that the reduction of delamination height $h$ reduces the buckling eigenvalue. With the decrease in height $h$, the effect becomes more 


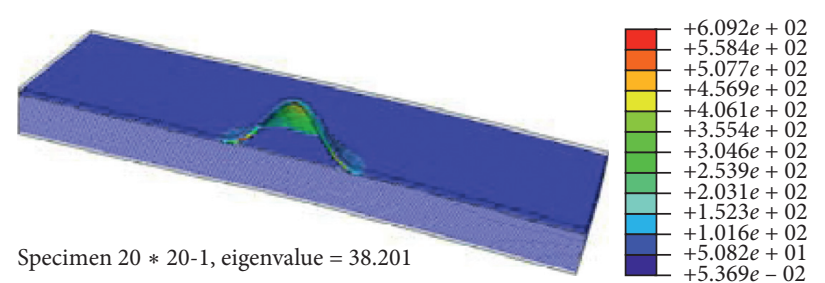

(a)

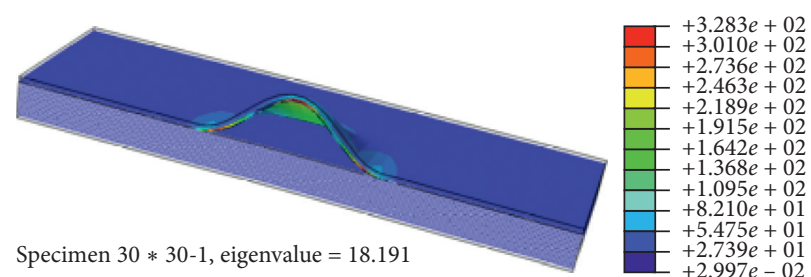

(b)

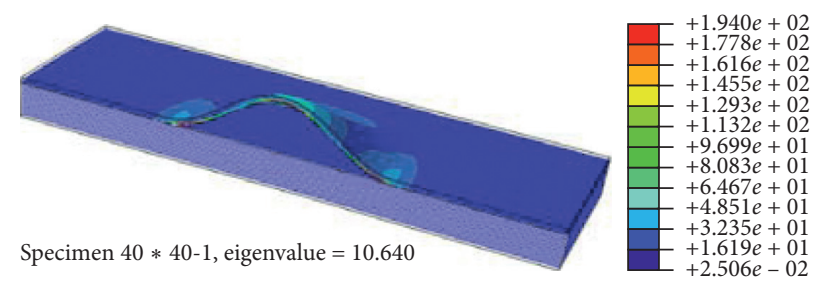

(c)

Figure 5: Specimens with different delamination defects.

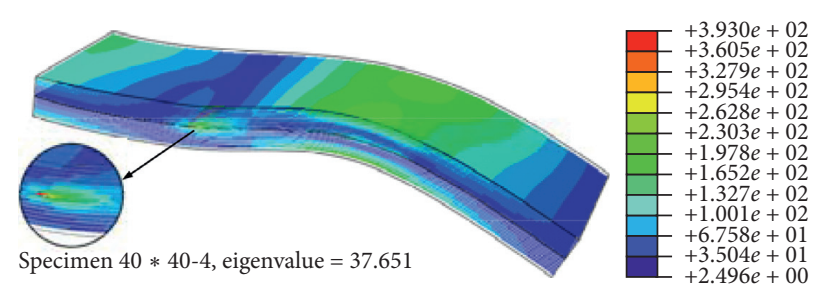

(a)

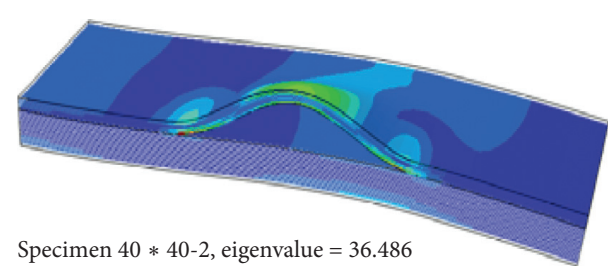

(c)

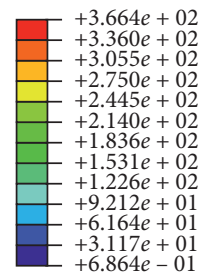

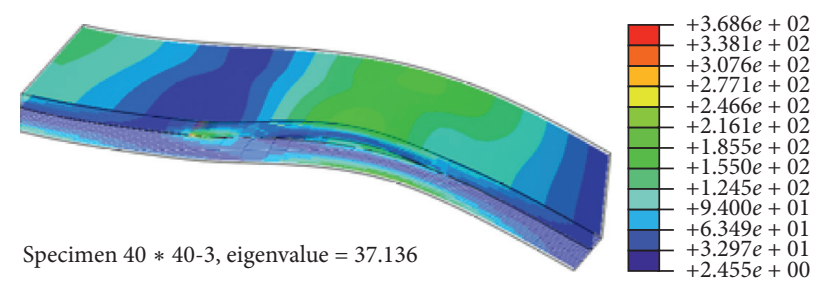

(b)
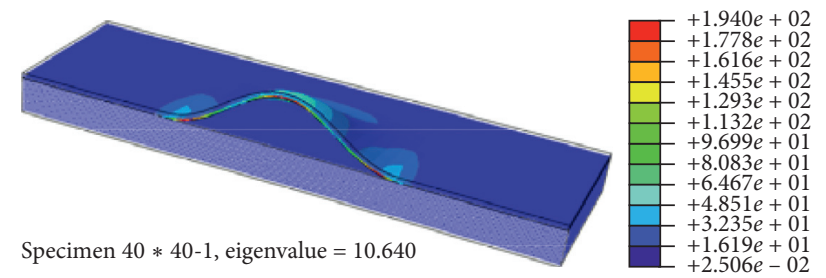

(d)

FIgURE 6: Specimens with different delamination defects.

evident. Delamination defects close to the surface shall be avoided in the production.

In order to determine the stress at the delamination area of different specimens, the stress value of the midsection of the first layer above the delamination area is taken in Figure 7(a). In Figure 7(a), the total stress $S$ of specimens $[40 * 40-4 / 40 * 40-3]$ is similar, with stress concentration at $30 \mathrm{~mm}$. There is a small stress concentration at $50 \mathrm{~mm}$ and $70 \mathrm{~mm}$, but it is far less than the peak at $30 \mathrm{~mm}$. Because of height $h$, the specimens $[40 * 40-2 / 40 * 40-1]$ are different from the specimens $[40 * 40-4 / 40 * 40-3]$, with almost the same stress concentration at $30 \mathrm{~mm}, 50 \mathrm{~mm}$, and $70 \mathrm{~mm}$.

The specimens $[40 * 40-2 / 40 * 40-1]$ are different from the specimens $[40 * 40-4 / 40 * 40-3]$ in Figure 6 are global buckled when loading. The stiffness of the layer in the delaminated boundary area at $30 \mathrm{~mm}$ is stronger than that at $70 \mathrm{~mm}$ in Figure 7. The apparent deformation of the layer at
$70 \mathrm{~mm}$ releases the material stress, making a low value of peak stress.

The specimen $[40 * 40-2 / 40 * 40-1]$ in Figure 6 has local buckling when loading. The stress value of the specimen $[40 * 40-2]$ is significantly more robust than that of the specimen $[40 * 40-1]$ in Figure $7(\mathrm{a})$. The specimen [40*40-2] in Figure 7 is slightly deformed at $70 \mathrm{~mm}$ to release part of the stress so that the peak value at $70 \mathrm{~mm}$ in Figure $7(\mathrm{a})$ is lower than that at $30 \mathrm{~mm}$.

The stress values in Figure 7 present the midsection of the first layer above the delamination area in Figure 6. It can be seen from Figure 7 that the value of $S 11$ is higher than that of $S 22$ and $S 33$ at the boundary of delamination, where the material is subjected to higher tension along the direction 1 . In the middle region of delamination, the values of $S 11$ and $S 22$ are higher that of $S 33$, where the material is subjected to a higher pressure along direction 1 and the pressure along 

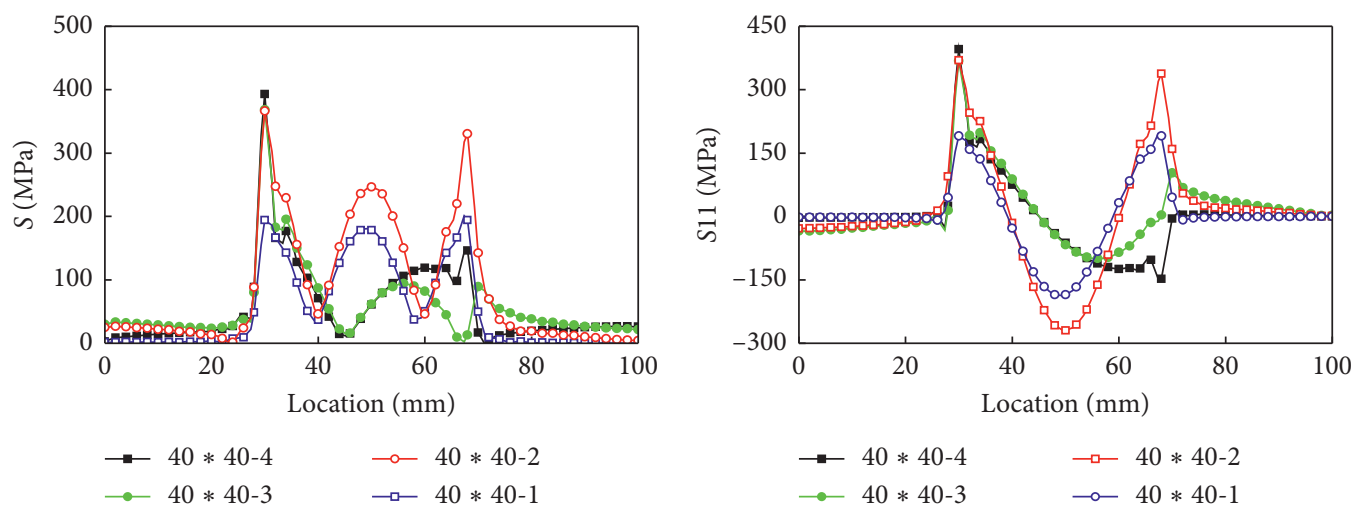

(a)

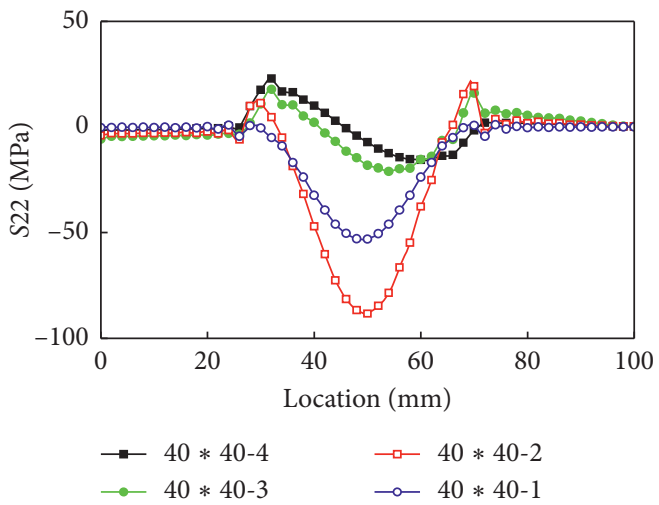

(c)

(b)

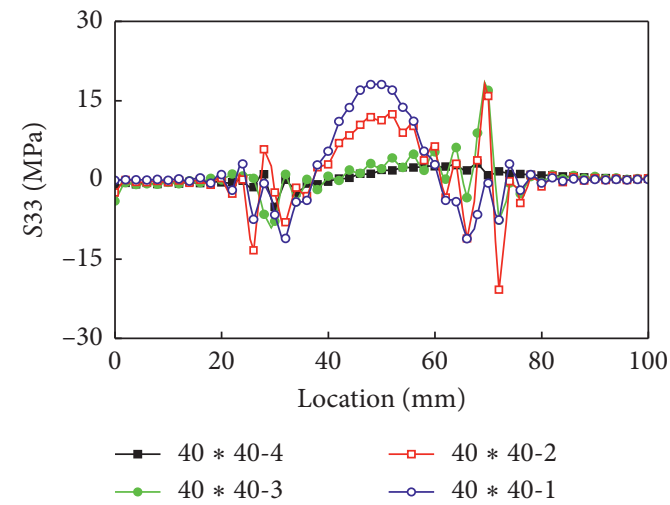

(d)

FiguRe 7: Value of overall stress in midsection.

the direction 2 . The $S 33$ perpendicular to the fiber direction and the layer surface has a low value.

The material stresses $S 11$ and $S 22$ produced by pressure are the reasons that lead to the buckling failure of UDL. Among them, S11 with high value in the boundary of delamination is the primary cause of failure, and the value of $S 11$ decreases with the increase in delamination height $h$. Meanwhile, the local buckling in the delamination region due to the effect of $S 11$ makes the fiber in the middle region of delamination subjected to pressure along the direction 2, resulting in the stress concentration.

4.3. Buckling Behavior of Specimens. In order to study the effects of different delamination on buckling eigenvalues in more detail, the buckling behavior of specimen with no defects, specimen [40*40-4], and specimen [40*40-1] were taken and compared. According to equation (1), the buckle half-wavelengths $m$ and $n$ affect the specimens' buckling eigenvalues under the same delamination parameters. The buckling order is listed on the left side of the buckling behavior of each specimen in Figure 8, and its buckling eigenvalue is listed on the lower left.

The half-wavelengths $m$ and $n$ of the specimen with no defects were added step by step so that the material can load a larger buckling force. The buckling behavior of the specimen $[40 * 40-4]$ is similar to that of the specimen with no defects, and the values of parameters $m$ and $n$ are the same.

The buckling behavior of the specimen $[40 * 40-1]$ is different from that of the former two. It shows local buckling, and the former two show global buckling. It is worth noting that the specimen [ $40 * 40-1]$ shows a mixed mode of global buckling and local buckling after four-order. The specimen [40*40-1] will still show the global buckling similar to that of the specimen with no defects after the local buckling eigenvalue reaches a specific value. It shows the added global buckling half-wavelength $m$ to load a large buckling force.

\section{Coupon Test}

5.1. Test Setup. In order to verify the simulation results, defect specimens are made, and coupon tests (supported by Lianyungang Zhongfu Lianzhong Composites Group Co., Ltd) are carried out to explore the failure mode of UDL with delamination defects. The specimens are the standard 8-layer UDL for an indoor test, with a width of $15 \mathrm{~mm}$ and a thickness of $4 \mathrm{~mm}$ in Figure 9. The specimens are made by hand lay-up and vacuum infusion, and inside contains delamination defects made by specific methods, which simulate the delamination defects of the spar cap.

In the test, the specimens are positioned and fixed on the press machine in Figure 10. A strain gauge is attached to the defect area of specimens to record the material's stress 


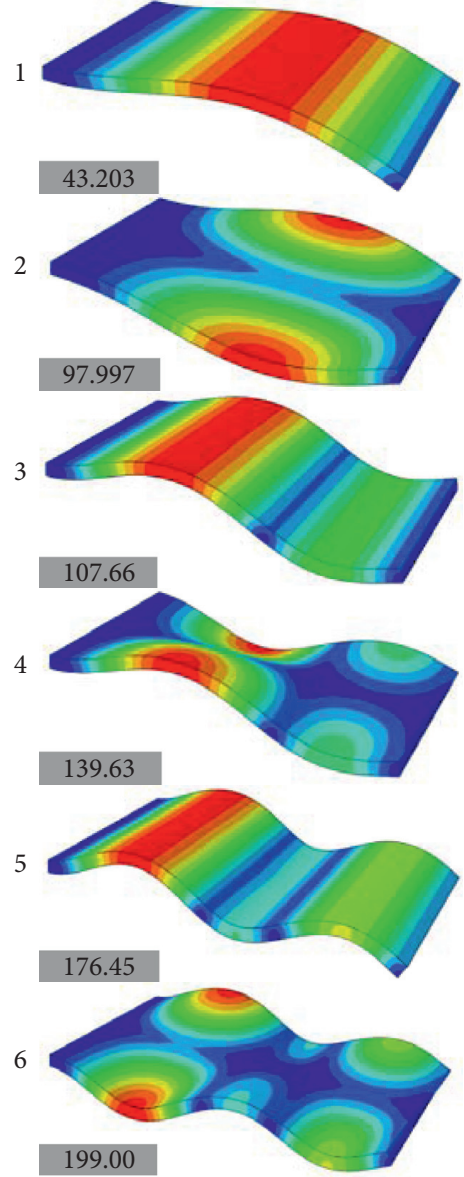

(a)
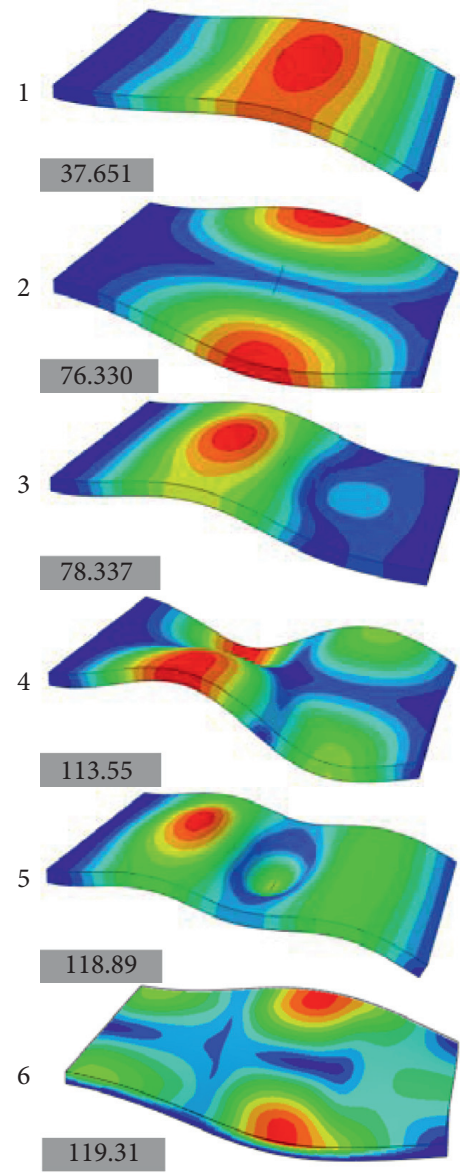

(b)
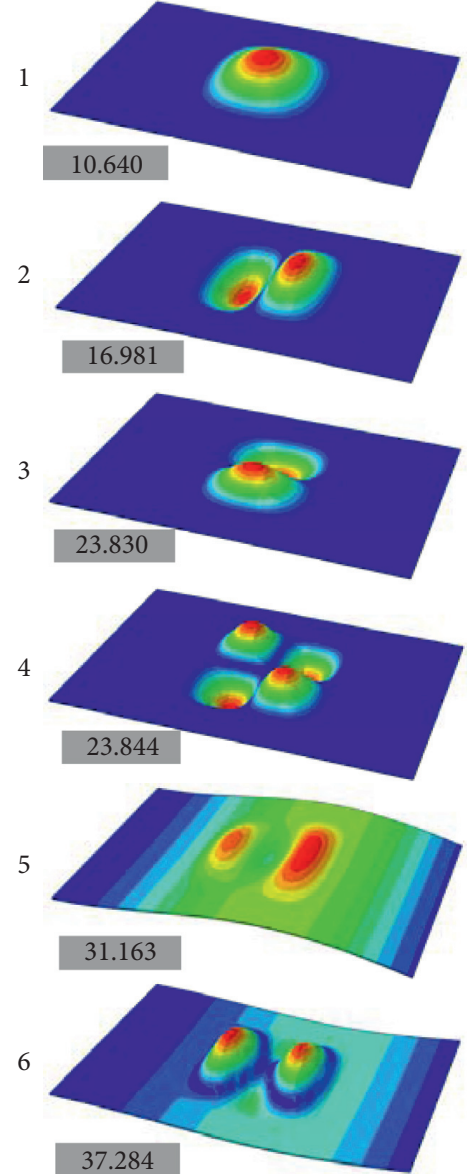

(c)

FIgURE 8: Buckling behavior of specimens: (a) specimen with no defects; (b) [40*40-4]; (c) [40* 40-1].
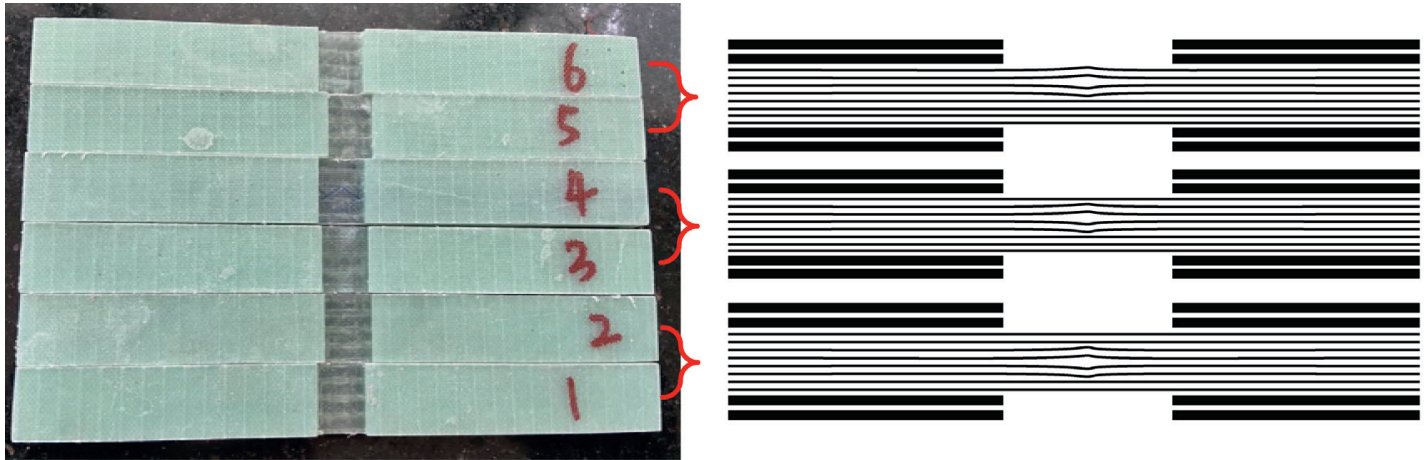

FiguRE 9: Specimens for the coupon test.

response when it fails $[34,35]$. After the start of the test, the specimen has a buckling deformation. Stress concentration effect is produced at the delamination area, which accelerates the specimens to buckle and fail. The data collection system records the strain response of specimens.

5.2. Test Results. A macroscopic investigation of the failure details of the specimen in Figure 11 reveals the following: specimen 1 and specimen 2 are fractured to both sides with the delamination defect in the middle; specimen 3 and specimen 4 showed inclined crack direction with global fracture; the layer of specimen 5 and specimen 6 close to the surface breaks outwards.

The strain gauge and press machine collected the stress and strain of the specimens in Figure 12. The strength of specimens 1 and 2 is close to those of no defect samples (the failure stress is $921.6 \mathrm{MPa}$ ), the difference of strength between specimens 1 and 2 and specimens 3 and 4 is small, and the strength data of specimens 3 and 4 are 


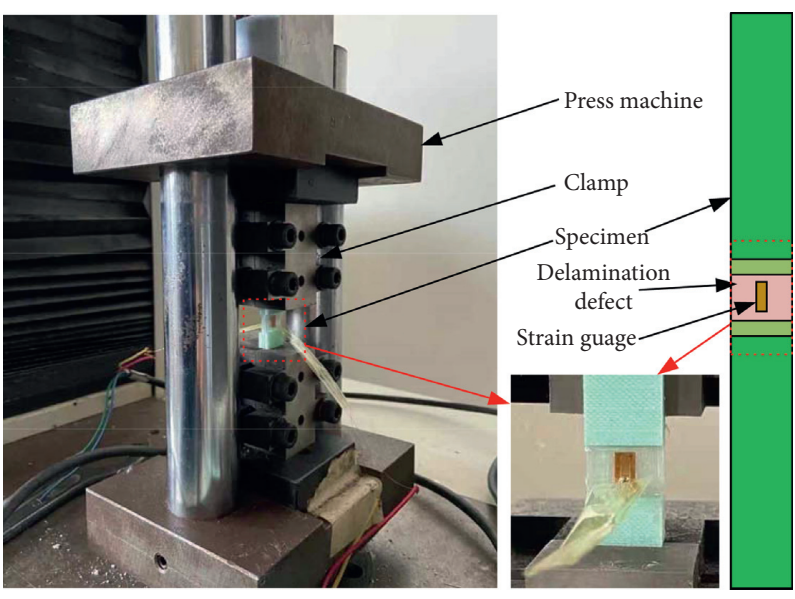

Figure 10: Fixation of the specimen.

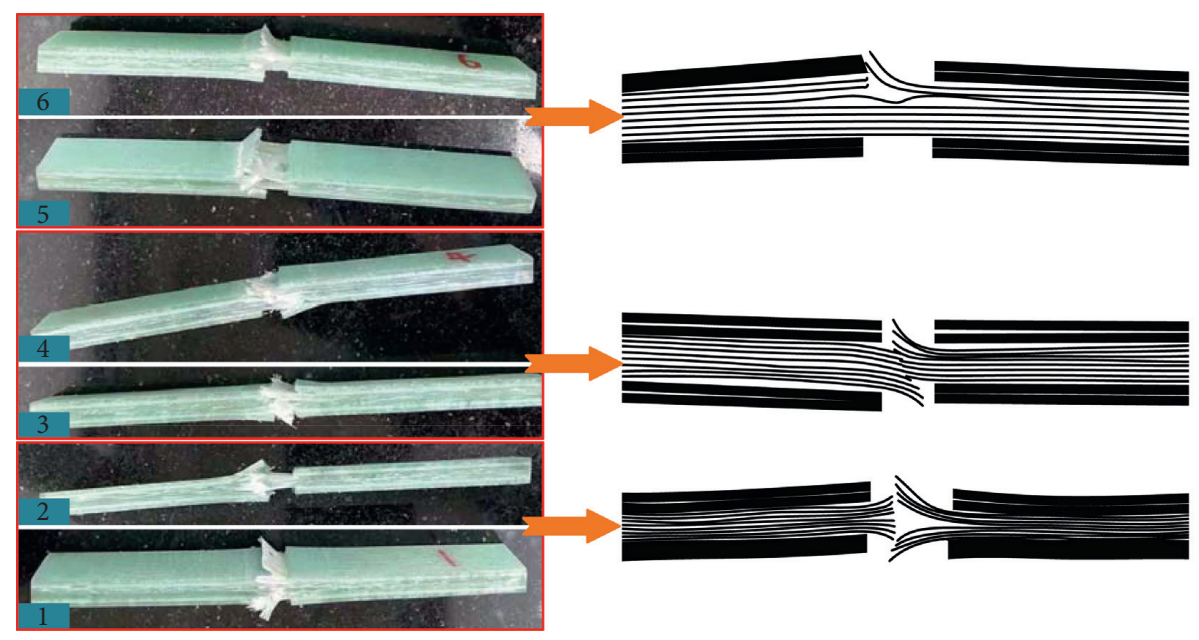

FIGURE 11: Details of fracture.

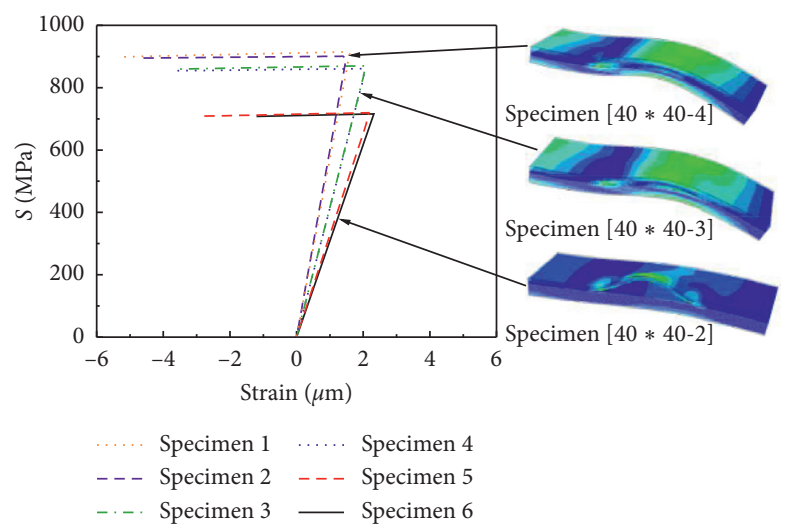

FIGURE 12: Materials behavior of tested UDL.

quite different from those of specimens 5 and 6 . The results show that the closer the delamination defect is to the surface of UDL, the worse the buckling resistance is. The defects close to the middle surface of the layer have little effect on the buckling resistance of the UDL.
Majority of coupon test results is similar to the FE results in Section 3.

Based on the results obtained from FE analysis, it is known that the $S 11$ along the fiber direction is the major cause of the failure. Excess $S 11$ causes the specimen to 
buckle. Instability of the structure leads to the breaks of fiber, and the strength of the specimen drops rapidly, which leads to failure. Specimen 1 and specimen 2 corresponding to the specimen $[40 * 40-4]$ in Figure 7 have the most significant stiffness in all tested specimens. Different structures cause different fracture modes of specimens. In the coupon test, the delamination defect is connected along the width direction, making the boundary of the specimens vulnerable, and the total failure in Figure 11 occurs. Specimen 3, specimen 4 , and specimen [ $40 * 40-3]$ in Figure 7 show the same fracture mode. Specimen 5 and specimen 6 are the same as specimen [40*40-2] in Figure 7 .

\section{Conclusion}

In this paper, FEM and coupon test have been conducted to study the buckling failure of UDL with different delamination defects. It can be summed in this work.

Compared with the normal UDL, the larger the delamination area is, the closer the delamination is to the surface, the more likely it is to cause buckling failure, which is shown as the reduction of buckling eigenvalues. The buckling eigenvalues of the defective UDL decrease with the reduction in the delamination height. The laminates with delamination defects show local buckling under the load and a mixed mode of local buckling and global buckling under a heavy load. When the laminate is buckling, stress concentration occurs at the boundary of delamination due to the $S 11$ along direction 1. There is a little stress concentration in the middle of the delamination area due to $S 11$ and $S 22$ along direction 2. The S33 has a low effect on the buckling failure of UDL.

So, some conclusions can be noted in this work:

(1) The larger the delamination area is, the higher the height will reduce the buckling performance of the spar cap. In the spar cap production process, the delamination defects of the large area should be avoided. In the transportation and assembly process of the spar cap, the impact on the products should be avoided.

(2) The value of the buckling half-wavelength $m$ shows the performance of the defective laminates. In the laminates with local buckling, it also shows global buckling with the addition of $m$.

(3) S11 leads to the buckling failure of the laminates with defects. Improvement of compressive strength along the fiber will slow down the process of laminates buckling failure.

\section{Data Availability}

The material properties listed in Table 1 and the data of coupon test used to support the findings of this study were supplied by Lianyungang Zhongfu Lianzhong Composites Group Co., Ltd, and they are included within the article.

\section{Conflicts of Interest}

The authors declare that they have no conflicts of interest.

\section{Acknowledgments}

This research was funded by the National Key R\&D Program of China (grant no. 2018YFB1501203) and Natural Science Foundation of Shandong (grant no. ZR2019MEE076). And the work has partly received funding from the National Key R\&D Program of Shandong (grant no. 2019GGX104001).

\section{References}

[1] L. Mishnaevsky, K. Branner, and H. N. Petersen, "Materials for wind turbine blades: an overview," Materials, vol. 10, 2017.

[2] B. Sørensen, "Materials and structures for wind turbine rotor blades-an overview," in Proceedings of the 17th International Conference on Composite Materials, Edinburgh, UK, July, 2009.

[3] C. A. Steeves and N. A. Fleck, "Collapse mechanisms of sandwich beams with composite faces and a foam core, loaded in three-point bending part II: experimental investigation and numerical modelling," International Journal of Mechanical Sciences, vol. 46, no. 4, pp. 585-608, 2004.

[4] E. E. Gdoutos and I. M. Daniel, "Nonlinear stress and deformation behaviour of composite sandwich beams," Applied Mechanics and Materials, vol. 13-14, pp. 91-98, 2008.

[5] J. W. Holmes, B. Sørensen, and P. Brøndsted, Reliability of Wind Turbine Blades: An Overview of Materials Testing, Chinese Renewable Energy Industry Association, Beijing, China, 2007.

[6] J. Su, S. E. Stapleton, S. J. Johnson et al., "Effects of localized manufacturing-induced defects in wind turbine blades," American Society for Composites, Washington, DA, USA, 2018.

[7] K. Branner and P. Berring, "Compressive strength of thick composite panels," in Proceedings of the 32th Risø International Symposium on Materials Science, Roskilde, Denmark, 2011.

[8] V. Boniface, "Fracture mechanics analysis of fuselage structural joints with cracks," Advances in Structural Integrity, vol. 2018, pp. 279-289, 2018.

[9] J. W. Nelson, T. W. Riddle, and D. S. Cairns, "Characterization of manufacturing defects common to composite wind turbine blades: effects of defects," in Proceedings of the AIAA SDM Conference, Denver, Co, USA, April 2011.

[10] J. W. Nelson, T. W. Riddle, and D. S. Cairns, "Effects of defects in composite wind turbine blades - part 2: progressive damage modeling of fiberglass-reinforced epoxy composites with manufacturing-induced waves," Wind Energy Science, vol. 2, no. 2, 2017.

[11] T. W. Riddle, J. W. Nelson, and D. S. Cairns, "Effects of defects in composite wind turbine blades - part 3: a framework for treating defects as uncertainty variables for blade analysis," Wind Energy Science, vol. 3, no. 1, 2018.

[12] A. Altmann, U. Mandel, R. Taubert et al., "A continuum damage model to predict the influence of ply waviness on stiffness and strength in ultra-thick unidirectional Fiberreinforced Plastics," Journal of Composite Materials, vol. 50, pp. 2739-2755, 2016.

[13] X. Chen, X. Zhao, and J. Xu, "Revisiting the structural collapse of a $52.3 \mathrm{~m}$ composite wind turbine blade in a full-scale bending test," Wind Energy, vol. 20, no. 6, pp. 1111-1127, 2017.

[14] L. A. Zhang, Y. Guo, L. Yu et al., "Structural collapse characteristics of a $48.8 \mathrm{~m}$ wind turbine blade under ultimate 
bending loading," Engineering Failure Analysis, vol. 106, p. 104150, 2019.

[15] P. U. Haselbach and K. Branner, "Initiation of trailing edge failure in full-scale wind turbine blade test," Engineering Fracture Mechanics, vol. 162, pp. 136-154, 2016.

[16] P. U. Haselbach, "An advanced structural trailing edge modelling method for wind turbine blades," Composite Structures, vol. 180, pp. 521-530, 2017.

[17] X. Chen, P. Berring, S. H. Madsen, K. Branner, and S. Semenov, "Understanding progressive failure mechanisms of a wind turbine blade trailing edge section through subcomponent tests and nonlinear FE analysis," Composite Structures, vol. 214, pp. 422-438, 2019.

[18] DNV GL Standard, DNVGL-ST-0376, Rotor Blades for Wind Turbines, DNV GL, Oslo, Norway, 2015.

[19] K. Branner, P. Berring, and P. U. Haselbach, Subcomponent Testing of Trailing Edge Panels in Wind Turbine Blades, 2016.

[20] J. J. Bender, S. R. Hallett, and E. Lindgaard, "Investigation of the effect of wrinkle features on wind turbine blade sub-structure strength," Composite Structures, vol. 218, pp. 39-49, 2019.

[21] G. Fernandez, H. Usabiaga, and D. Vandepitte, "Subcomponent development for sandwich composite wind turbine blade bonded joints analysis," Composite Structures, vol. 180, pp. 41-62, 2017.

[22] M. Gaiotti, C. M. Rizzo, K. Branner, and P. Berring, "An high order mixed interpolation tensorial components (MITC) shell element approach for modeling the buckling behavior of delaminated composites," Composite Structures, vol. 108, pp. 657-666, 2014.

[23] K. Wang, L. Zhao, H. Hong et al., "An analytical model for evaluating the buckling, delamination propagation, and failure behaviors of delaminated composites under uniaxial compression," Composite Structures, vol. 223, Article ID 110937, 2019.

[24] Y. Gong, L. Zhao, J. Zhang, and N. Hu, “An improved power law criterion for the delamination propagation with the effect of large-scale fiber bridging in composite multidirectional laminates," Composite Structures, vol. 184, pp. 961-968, 2018.

[25] Y. Gong, L. Zhao, J. Zhang, Y. Wang, and N. Hu, "Delamination propagation criterion including the effect of fiber bridging for mixed-mode I/II delamination in CFRP multidirectional laminates," Composites Science and Technology, vol. 151, pp. 302-309, 2017.

[26] Y. Gong, X. Chen, J. Tao et al., "A simple procedure for determining the mode I bridging stress of composite DCB laminates without measuring the crack opening displacement," Composite Structures, vol. 243, p. 112147, 2020.

[27] A. Nasirmanesh and S. Mohammadi, "Eigenvalue buckling analysis of cracked functionally graded cylindrical shells in the framework of the extended finite element method," Composite Structures, vol. 159, pp. 548-566, 2017.

[28] P. U. Haselbach, R. D. Bitsche, and K. Branner, "The effect of delaminations on local buckling in wind turbine blades," Renewable Energy, vol. 85, pp. 295-305, 2016.

[29] A. Hajlaoui, A. Jarraya, K. El Bikri, and F. Dammak, "Buckling analysis of functionally graded materials structures with enhanced solid-shell elements and transverse shear correction," Composite Structures, vol. 132, pp. 87-97, 2015.

[30] Z. Qin, J. Wang, K. Yang et al., "Design and nonlinear structural responses of multi-bolted joint composite boxbeam for sectional wind turbine blades," Composite Structures, vol. 206, pp. 801-813, 2018.

[31] J. Tang and X. Chen, "Experimental investigation on ultimate strength and failure response of composite box beams used in wind turbine blades," Composite Structures, vol. 198, pp. 1934, 2018.

[32] X. Chen, J. Tang, and K. Yang, "Modeling multiple failures of composite box beams used in wind turbine blades," Composite Structures, vol. 217, pp. 130-142, 2019.

[33] C. Bisagni and R. Vescovini, "Analytical formulation for local buckling and post-buckling analysis of stiffened laminated panels," Thin-Walled Structures, vol. 47, no. 3, 2009.

[34] M. Sung, J. Jang, V. L. Tran, S.-T. Hong, and W.-R. Yu, "Increased breaking strain of carbon fiber-reinforced plastic and steel hybrid laminate composites," Composite Structures, vol. 235, p. 111768, 2020.

[35] M. A. Muflikhun, T. Yokozeki, and T. Aoki, "The strain performance of thin CFRP-SPCC hybrid laminates for automobile structures," Composite Structures, vol. 220, pp. 1118, 2019. 